\title{
The influence of leaf anatomical traits on photosynthetic in coffee leaves in
} Yunnan of China

Ziwei Xiao ${ }^{1 *}$, Guanrun $\mathrm{Ma}^{1}{ }^{*}$, Xuehui Bai ${ }^{1}$, Jinhong $\mathrm{Li}^{1}$, Mingzhu Zhao ${ }^{1}$, Linlin $\mathrm{Su}^{1}$, Hongying $\mathrm{Ma}^{2}$, Hua Zhou ${ }^{1}$

\section{Dehong Tropical Agriculture Research Institute of Yunnan, Ruili, Yunnan 678600,} China

2. Ruining No.1 Nationality Middie Schooi

*Correspondence:xiaozw86@126.com or marui1956@126.com

\section{Abstract}

Leaf photosynthesis is largely determined by anatomical features. This work aimed to reveal the quantitative effects of Coffea arabica leaf anatomical structure on photosynthesis. Pearson's correlation and path analysis was used to explore the correlation between leaf structure and photosynthesis. The comprehensive evaluation value of the correlation between leaf anatomical traits and photosynthetic parameters is calculated by using the Criteria Importance Though Intercrieria Correlation (CRITIC) method to obtain the objective weight of each photosynthetic parameter. Most of the leaf's anatomical traits significantly $(P<0.05)$ to highly significantly $(P<0.01)$ correlated with photosynthetic parameters, suggesting that anatomical traits greatly affected photosynthetic capacity in Coffea arabica leaf. Likewise, path coefficient analysis revealed that all the leaf anatomical traits influenced photosynthetic capacity directly and indirectly. The results of the comprehensive evaluation showed that leaf thickness (LT) and stomatal density $(d)$ are the anatomical characteristics most closely related to photosynthesis. These results may help pinpoint anatomical features required to gain higher photosynthesis in coffee leaves.

Keywords: Coffea arabica L., leaf anatomy, photosynthesis, correlation and path coefficient, CRITIC method, comprehensive evaluation

\section{Introduction}

Coffee (Coffea arabica) considered an important tropical crop is one of the most traded agricultural products in the world. Under suboptimal growing conditions, shade trees, which could reduce the stress of coffee by ameliorating adverse climatic conditions, have been recommended (Beer et al., 2001; Franck and Vaast, 2009a). Yunnan province, located in Southwest China, is a predominantly coffee-growing region (ICO, 2015). Although the mountainous landscape and mild climate in this region are well-suited to coffee production, many areas are suboptimal for coffee cultivation (ICO, 2015; Ma et al., 2019). Thus, agroforestry systems have been recommended for these areas, especially at altitudes below 1000m (Ma et al., 2019). However, the physiological trait characteristic of shade-adapted coffee is the lower photosynthetic capacity when compared to $\mathrm{C}_{3}$ woody plants grown in tropical climates (Ayalew, 2018; DaMatta, 2004). Leaves have evolved as photosynthetic organs in land plants (Oguchi et al., 2018) so the leaf of coffee is the main organ of photosynthesis.

Because leaves are specialized organs that enable plants to intercept light and uptake $\mathrm{CO}_{2}$ through the stomata for photosynthesis (Lambers and Oliveira, 2019), light and $\mathrm{CO}_{2}$ availability in the mesophyll of plant leaves largely determine the net carbon 
assimilation rate (A) of leaves (Franck and Vaast, 2009b). To analyze the response of photosynthesis to irradiance, the light response curves (LRCs) were used to describe the relationship between photosynthesis and light intensity (Herrmann et al., 2020). It is an important method to elucidate the response mechanism of photosynthesis and evaluate photosynthetic efficiency by fitting of light-response model (Lambers and Oliveira, 2019). Often, LRCs are described mathematically using the empirical model. The operation state of plant photosynthetic apparatus and photosynthetic parameters, such as the information of the maximum photosynthetic capacity $\left(P_{\mathrm{nmax}}\right)$, intrinsic and apparent quantum yield (IQY and AQY), light compensation and saturation point (LCP and LSP), and dark respiration rate $\left(R_{\mathrm{D}}\right)$, can be obtained from the LRCs. In addition, mechanistic information about the key biochemical parameters of carbon assimilation can be estimated by fitting $A / C \mathrm{i}$ curves with the mechanistic Farquhar-von Caemmerer-Berry (FvCB) biochemical model described by Farquhar et al. (1980) (Farquhar et al., 1980; Sun et al., 2014; Wang et al., 2017). This model has been widely used to simulate $\mathrm{CO}_{2}$ assimilation and applied for decades (Farquhar et al., 1980; GU et al., 2010). It elegantly explains the physiological properties of photosynthesis of intact leaves (Lambers and Oliveira, 2019), and the parameters reflecting biochemical properties of leaves were easier to estimate from this model with gas exchange measurements (Wang et al., 2017).

The structural organization of plant leaves could facilitate or sometimes constrain the photochemical reactions of the photosynthetic process (Boom et al.; Oguchi et al., 2018). Therefore, the leave structural changes may affect photosynthetic efficiency (Akhkha et al., 2001; Herrmann et al., 2020). However, although a variety of ecological studies have revealed a correlation between leaf structural parameters and photosynthetic performance (Bolhar-Nordenkampf and Draxler, 1993; James and Bell, 2001; Vogelman et al., 1996), there were contradictory and not universal differences between foliage structural and functional variables in the previous work (Niinemets, 1999). To understand the effects of leaf structure on each photosynthetic performance parameter, it is necessary to analyze the relationship between leaf structure and leaf photosynthesis and comprehensively evaluate the importance of each component in leaf photosynthesis. Because the evaluation of the relationship between leaf structure and leaf photosynthesis could provide ecophysiological evidence for understanding the structural properties of leaves how to influence photosynthetic performance. Even though a number of studies analyze the effects of leaf structure on photosynthetic performance (Bolhar-Nordenkampf and Draxler, 1993; Oguchi et al., 2018), there are few works synthetically analyzing the correlation between leaf structural parameters and photosynthetic performance (Boom et al.). In particular, a few works were related to coffee. Therefore, the aims of this study were to explore the relationship between leaf structural parameters and photosynthetic performance, clarify the importance of the correlation between leaf structural parameters and photosynthetic performance by using a comprehensive evaluation method. Gaining these results may provide useful information for future coffee breeding and plantation management.

\section{Materials and methods}

\subsection{Study site characterization and Plant material}


The experiment was conducted in the shade coffee plantations of Dehong Tropical Agriculture Research Institute of Yunnan (DTARI), Ruili, southwest China. The plantations are located at 890 meters of altitude, at 24.025 south latitude and 97.855 west longitude, with an average temperature of $22.2^{\circ} \mathrm{C}$ and precipitation of $1260 \mathrm{~mm}$ in the studies conducted years (2017-2018). The soil in the plantation is characterized as acidic lateritic red soil.

The coffee trees of the cultivar are 'Catimor', a hybrid derived from the cross between two cultivars: Caturra (Coffea arabica L.) and Timor $(C$. arabica $\times$ C. canephora Pierre ex Froehner). The coffee trees were approximately five years old and spaced $1 \times 2 \mathrm{~m}$. Shade trees (Dimocarpus longan Lour.) planted at $12 \times 4 \mathrm{~m}$, East to West rows-oriented.

A completely randomized design was the following: six coffee plants per treatment combination and used as replicates. All the sampling and measurement leaves used the third or fourth completely expanded leaf pair from the apex of the plagiotropic (lateral) branches located in the upper third of the plant. Nine leaves in different directions on each tree were selected to measure the chlorophyll content values and leaf gas exchange parameters.

\subsection{Gas exchange measurements}

The leaf gas exchange parameters (net $\mathrm{CO}_{2}$ assimilation rate (A), stomatal conductance to water vapor $\left(g_{\mathrm{s}}\right)$, transpiration rate $(\mathrm{E})$, internal $\mathrm{CO}_{2}$ concentration $\left(C_{\mathrm{i}}\right)$, vapor pressure deficit (VPD), and leaf water use efficiency $\left(\mathrm{WUE}=\mathrm{A} . \mathrm{E}^{-1}\right)$ ) and environmental indicators(leaf temperature (TL), relative humidity (RH) and ambient temperature (TA)) were determined simultaneously by using a portable photosynthesis system CIRAS 3 (PP Systems, USA). Leaf water use efficiency (WUE), representing the units assimilated $\mathrm{CO}_{2}$ per unit water lost through transpiration, is following the user manual version 1.06. All measurements were taken on sunny days from 09:00 to 11:30 and 15:00 to 18:00. The reference $\mathrm{CO} 2$ concentration was set at $390 \mathrm{ppm}$ using a buffer bottle, the temperature at $27 \circ \mathrm{C}$, flow rate at $300 \mu \mathrm{mol} . \mathrm{s}^{-1}$, relative humidity at $50 \pm 10 \%$, and irradiance at $800 \mu \mathrm{mol} \mathrm{m} \mathrm{m}^{-2} \cdot \mathrm{s}^{-1}$. The leaf of photosynthetic light response $(\mathrm{A} / \mathrm{PPFD})$ and internal $\mathrm{CO}_{2}$ response $\left(\mathrm{A} / \mathrm{C}_{\mathrm{i}}\right)$ curves were constructed by using leaf gas exchange. To collect data for building A/PPFD curves, net photosynthesis was measured at $0,50,100,150,200,250,300,350,400,500,600$, 700, 800, 1000, and $1200 \mu \mathrm{mol} \mathrm{m} \mathrm{m}^{-2} \cdot \mathrm{s}^{-1}$ (PAR) with a cuvette environment that maintained leaf temperature at $27^{\circ} \mathrm{C}$, reference $\mathrm{CO} 2$ concentration at $400 \mathrm{ppm}$. After the leaf tissue was clamped in the leaf chamber, the gas exchange rates usually stabilized within approximately 3-4 min. Data to construct $A / C_{i}$ curves were collected from the same sample leaves immediately following A/PPFD measurements. $P_{n}$ was measured at $\mathrm{CO}_{2}$ concentrations of 400, 300, 200, 100, 150, 250, 350, 450, 550, 650, $750,850,950,1050,1250,1450$ and $1650 \mu \mathrm{mol} . \mathrm{m}^{-2} \cdot \mathrm{s}^{-1}$ at photosynthesis saturating irradiance $800 \mu \mathrm{mol} \mathrm{m} \mathrm{m}^{-2} \cdot \mathrm{s}^{-1}$, which light intensity is sufficiently high to saturate the photosynthetic machinery without causing photoinhibition. A total of $41 \mathrm{~A} / \mathrm{PPFD}$ and $42 \mathrm{~A} / \mathrm{C}_{\mathrm{i}}$ curves were generated, respectively.

\subsection{Measurement of leaf anatomical traits}

Following gas exchange measurement, five sample leaves of each plant were 
harvested, sealed in polyethylene bags, and immediately brought back to the laboratory. Two segments $(3 \mathrm{~mm} \times 5 \mathrm{~mm})$ were cut from each leaf halfway between the leaf apex and base. Then, the material was dehydrated on sucrose solutions, followed by the inclusion of Gum Arabic aqueous solution. Leaf transverse sections (7-10 $\mu \mathrm{m})$ thickness cut using a rotary microtome (Leica CM3050S, Germany) and stained with toluidine blue. Surface sections of the leaves were taken manually and stained with safranine aqueous solution $(0.1 \%)$. For each leaf, five transversal sections and surface sections were selected systematically to measure the leaf thickness (LT), upper cuticle thickness (UCT), upper epidermal thickness (UET), palisade tissue thickness (PT), spongy tissue thickness (ST), lower epidermal thickness (LET), lower cuticle thickness (LCT), stomatal density $(d)$, and guard cell length $(l)$ and width $(w)$, using a microscope binocular with $10 \times$ and $40 \times$ objectives (Leica DM5000 B). Subsequently, five photographs of microscope fields per section were taken with a photomicroscope equipped with a Leica DFC500 camera (Leica Microsystems, Rijswijk, The Netherlands). Images were analyzed with Leica LAS X software.

\subsection{Calculations and statistical analysis}

A/PPFD curves were fitted by applying a modified rectangular hyperbola model using Photosynthetic Calculation Software 4.1.1(Ye, 2007; Ye, 2010; Ye and Yu, 2008). The equation of the modified rectangular hyperbola model is described by:

$$
P_{\mathrm{n}}(I)=\alpha \frac{1-\beta I}{1+\gamma I} I-R_{\mathrm{d}}
$$

where $P_{n}$ is the net photosynthetic rate $\left(\mu \mathrm{mol} \cdot \mathrm{CO}_{2} \mathrm{~m}^{-2} \cdot \mathrm{s}^{-1}\right), I$ is the photosynthetic photon flux density $\left(\mu \mathrm{mol} \cdot \mathrm{m}^{-2} \cdot \mathrm{s}^{-1}\right), I_{\mathrm{c}}$ is compensation irradiance, $\beta$ and $\gamma$ are the coefficients which are independent of $I$, and $\alpha$ is the absolute value of slope between $I$ $=0$ and $I=I_{\mathrm{c}}$.

For $I=0$, the quantum yield at this point is defined as intrinsic quantum yield (IQY), which is given by:

$\mathrm{IQY}=\alpha\left(1+(\gamma+\beta) I_{c}\right)$

The apparent quantum yield (AQY) ignored the Kok effect is obtained by:

$$
\mathrm{AQY}=\alpha \frac{1+(\gamma-\beta) I_{\mathrm{c}}-\gamma \beta I_{\mathrm{c}}^{2}}{\left(1+\gamma I_{\mathrm{c}}\right)^{2}}
$$

For $I=0$, the rate of dark respiration $\left(R_{\mathrm{d}}\right)$ is:

$R_{\mathrm{d}}=-P_{\mathrm{n}}\left(I_{0}\right)=-\alpha I_{\mathrm{c}}$

The saturation irradiance $I_{\text {sat }}$ is obtained by:

$I_{\text {sat }}=\frac{\sqrt{(\beta+\gamma) / \beta}-1}{\gamma}$

The maximum photosynthetic rate $P_{\text {nmax }}$ is given by:

$P_{\text {nmax }}=\alpha\left(\frac{\sqrt{\beta+\gamma}-\sqrt{\beta}}{\gamma}\right)^{2}-R_{\mathrm{d}}$

$\mathrm{A} / \mathrm{Ci}$ curves were fit by uploading the datasets to the website (http://Leafweb.ornl.gov) to estimate the parameters. In this study, $\mathrm{A} / \mathrm{C}_{\mathrm{i}}$ curves were at saturating light levels. Thus, the rate of electron transport $(J)$ was to assume the maximum rate of electron 
transport $\left(J_{\max }\right)$.

The total stomach pore area (TSP) was calculated as $d \times 1 / 4 \pi \times l \times w(7)$, and by assuming that the stomatal pore was an ellipse(Batos et al., 2010; James and Bell, 2001; Patricia et al., 2014). Where $d$ is the stomatal frequency calculated by dividing the stomatal count by the area of the field of view, $l$ is the guard cell length, and $w$ is the guard cell width.

The relationships of photosynthetic capacity with leaf anatomical traits were analyzed by Pearson's correlation. The possible direct and indirect effects of each leaf anatomical trait on the photosynthetic parameter were further identified by path analysis(Zhang et al., 2005). For path analysis, direct and indirect effects were obtained from partial least squares (PLS) regression of leaf anatomical traits on photosynthetic parameter and Pearson's correlations between leaf anatomical traits(Guohua et al., 2017). To combine effect leaf anatomical traits on photosynthetic parameters, a multiple criteria decision analysis (MCDA) has been utilized in this study. The objective weight of each photosynthetic parameter $\left(\mathrm{w}_{\mathrm{j}}\right)$ is obtained by using the Criteria Importance Though Intercrieria Correlation (CRITIC) method, which was a correlation method using a standard deviation of column and correlation coefficients of all paired columns(Diakoulaki et al., 1995). The comprehensive evaluation of the effects of leaf anatomical traits on photosynthetic parameters was calculated by using the following equation: $Q_{i}=\sum_{j=i}^{n}\left(w_{j} \times r_{i j}\right)(8)$, where $r_{i j}$ was the correlation coefficient between leaf anatomical trait $\mathrm{i}$ and photosynthetic parameter j. All statistical analyses were conducted with IBM SPSS Statistics 24.

\section{Results}

Results showed the photosynthetic light-response curve (Fig.1) fits very well with the modified rectangular hyperbola model $\left(\mathrm{R}^{2}=0.945 \pm 0.006\right)$ described by Ye $(2007)$ (Ye, 2007). The $P_{\mathrm{n}}$ increased with $I$ below the $I_{\text {sat }}$. When $I$ was above $I_{\text {sat }}$, the $P_{\mathrm{n}}$ decreased as $I$ increased, which means the photoinhibition phenomenon. The calculated AQY would be $0.028 \pm 0.003$ if the Kok effect were ignored. This value was lower than $\alpha(0.031 \pm 0.003)$ and the IQY $(0.033 \pm 0.003)$. The maximum $P_{\mathrm{n}}$ values calculated by modified rectangular hyperbola model at $I_{\text {sat }}$ of $621.762 \pm 37.358$ $\mu$ mol(photon) $\mathrm{m}^{-2} \mathrm{~s}^{-1}$ was $5.131 \pm 0.478 \mu \mathrm{mol}\left(\mathrm{CO}_{2}\right) \mathrm{m}^{-2} \mathrm{~s}^{-1}$ for coffee leaf. The values of $I_{\mathrm{c}}$ and $R_{\mathrm{D}}$ were $60.238 \pm 11.332 \mu \mathrm{mol}$ (photon) $\mathrm{m}^{-2} \mathrm{~s}^{-1}$ and $0.930 \pm 0.098 \mu \mathrm{mol}\left(\mathrm{CO}_{2}\right) \mathrm{m}^{-2} \mathrm{~s}^{-1}$, respectively. 


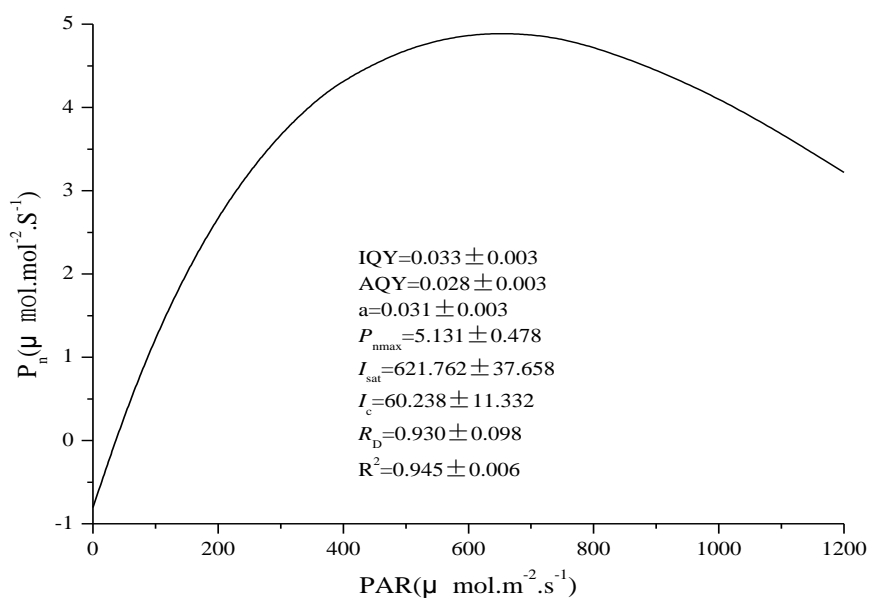

Fig.1 Photosynthetic light-response curve of coffee plants. Data shown in the figure indicate mean \pm stand error. IQY-intrinsic quantum yield; AQY-apparent quantum yield; $\alpha$-the absolute value of slope between $I=0$ and $I=I_{\mathrm{c}}$; $P_{\text {nmax }}$-maximum photosynthetic rate $\left[\mu \operatorname{mol}\left(\mathrm{CO}_{2}\right) \mathrm{m}^{-2} \mathrm{~s}^{-1}\right] ; I_{\text {sat }}-$ light saturation point $\left[\mu \mathrm{mol}\right.$ (photon) $\left.\mathrm{m}^{-2} \mathrm{~s}^{-1}\right] ; I_{\mathrm{c}}$ -light compensation point $\left[\mu \mathrm{mol}\right.$ (photon) $\left.\mathrm{m}^{-2} \mathrm{~s}^{-1}\right] ; R_{\mathrm{D}}-$ dark respiration $\left[\mu \mathrm{mol}\left(\mathrm{CO}_{2}\right) \mathrm{m}^{-2} \mathrm{~s}^{-1}\right]$.

Based on the FvCB model structure, the $\mathrm{A} / C_{\mathrm{i}}$ curve was fitted with the interactive website (http://www.leafweb.ornl.gov)(Gu and Sun, 2014). Figure 2 shows the response of $\mathrm{A}$ to $\mathrm{C}_{\mathrm{i}}$ for coffee leaves. The parameters of values for $V_{\mathrm{cmax}}, J_{\max }, T_{\mathrm{p}}, R_{\mathrm{d}}$, $\Gamma^{*}, g_{\mathrm{i}}$, and $K_{\mathrm{co}}$ were $61.749 \pm 5.394,80.721 \pm 17.963,5.316 \pm 0.576,3.225 \pm 0.441$, $3.309 \pm 0.333,1.101 \pm 0.287,103.096 \pm 11.721$, respectively. The transition between the Rubisco- and RuBP regeneration-limited states $\left(C_{\mathrm{i}_{-} \mathrm{CJ}}\right)$ occurs around $30 \mathrm{~Pa}$ intercellular $\mathrm{CO}_{2}$ and the TPU-limited state $\left(C_{\mathrm{i} \_\mathrm{JP}}\right)$ is around $90 \mathrm{~Pa}$ (Fig 2.).

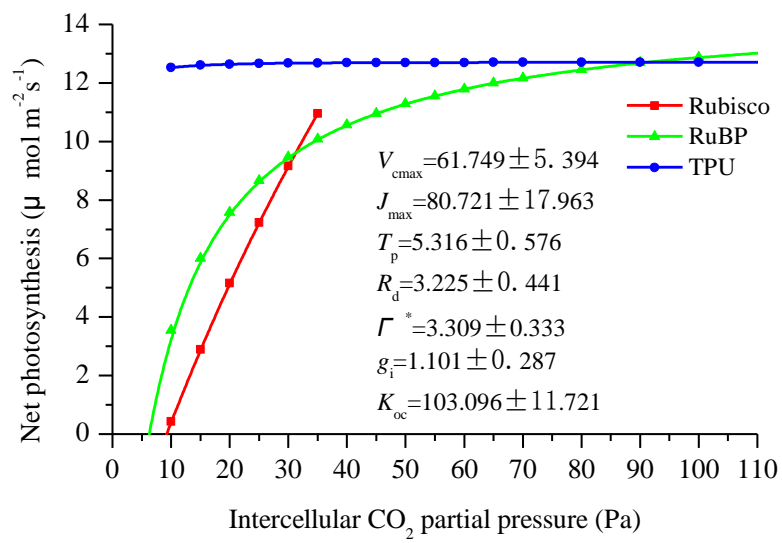

Fig 2. $\mathrm{A} / \mathrm{C}_{\mathrm{i}}$ curves for coffee plants. Data shown in the figure indicate mean \pm stand error. $C_{\mathrm{i}}-$ Intercellular $\mathrm{CO}_{2}$ concentration $\left(\mu \mathrm{mol} \mathrm{mol}{ }^{-1}\right) ; V_{\mathrm{cmax}}-$ Maximal Rubisco carboxylation rate $\left(\mu \mathrm{mol} \mathrm{m} \mathrm{m}^{-2} \mathrm{~s}^{-1}\right) ; J_{\max }-$ Maximal electron transport rate $\left(\mu \mathrm{mol} \mathrm{m} \mathrm{m}^{-2} \mathrm{~s}^{-1}\right) ; T_{\mathrm{p}}$-Rate of triose phosphate export from the chloroplast $\left(\mu \mathrm{mol} \mathrm{m} \mathrm{m}^{-2} \mathrm{~s}^{-1}\right) ; R_{\mathrm{d}}-$ Day respiration $\left(\mu \mathrm{mol} \mathrm{m} \mathrm{m}^{-2} \mathrm{~s}^{-1}\right) ; \Gamma^{*}-\mathrm{CO}_{2}$ compensation point in the absence of dark respiration $(\mathrm{Pa}) ; g_{\mathrm{i}}-$ Internal (mesophyll) conductance to $\mathrm{CO}_{2}$ transport $\left(\mu \mathrm{mol} \mathrm{m} \mathrm{m}^{-2} \mathrm{~s}^{-1} \mathrm{~Pa}^{-1}\right) ; K_{\mathrm{oc}}-\mathrm{A}$ composite parameter $(\mathrm{Pa})$ : $K_{\mathrm{oc}}=$ $K_{\mathrm{c}}\left(1+O / K_{\mathrm{o}}\right)$

Interrelationships with correlation analysis between photosynthetic capacity and leaf anatomical traits were presented in Table 1. There were many significant differences between photosynthetic capacity and leaf anatomical traits. The UCT 
correlated negatively with IQY, AQY, $\alpha, I_{\text {sat }}$, and $g_{\mathrm{i}}(p<0.05)$. The UET appeared to be positively related to AQY, $\alpha$, and $P_{\max }(p<0.05)$, and negatively related to $I_{\mathrm{c}}, R_{\mathrm{d}}, C_{\mathrm{i}}$, and VPD $(p<0.05)$ (Table 1). The relationship between PT and IQY, AQY and $\alpha$ was significantly negative $(p<0.05)$. The LET had a significantly negative effect on the $I_{\mathrm{c}}$ was significantly negative $(p<0.05)$. The LCT was important to $I_{\text {sat }}$, and the Pearson correlation coefficient was significantly negative $(p<0.05)$. The guard cell width $(w)$ significantly affected $I_{\mathrm{c}}$ and $R_{\mathrm{d}}$. The guard cell length $(l)$ correlated negatively with IQY, AQY, $\alpha$, and $I_{\text {sat }}$, and positively with $J_{\max }$ A strongly positive $(p<0.01)$ correlation relationship between stomatal density $(d)$ and $J_{\max }$ was found in this study. Based on Pearson correlation analysis, however, LT and ST had relatively little effect on the photosynthetic capacity.

Path analysis was performed to reveal the direct and indirect effects of leaf anatomical traits on photosynthetic capacity. The results indicating the effects were shown in Fig 3. Although correlation analysis suggested that there were no significant correlations between LT and photosynthetic capacity variables $(p>0.05)$, its direct effects on IQY (0.488), $\alpha(0.429), R_{\mathrm{d}}(0.390)$, and AQY(0.381) were relatively high. In addition, there were high negative direct effects of LT on $I_{\text {sat }}(-0.431)$ and $\Gamma^{*}(-0.379)$. The negative direct effect of UCT on IQY (-0.756), $\alpha(-0.720)$, and AQY (-0.679) was found to be higher than the other photosynthetic capacity variables. UET has a high negative direct effect on $R_{\mathrm{d}}(-0.785)$, TPU (-0.520), and a high positive direct effect on $\mathrm{E}$ $(0.563), g_{\mathrm{s}}(0.451)$, and $P_{\max }(0.448)$. PT exhibited an impressive negative direct effect on TPU (-0.518), AQY(-0.410), $\alpha(-0.410)$, and IQY (-0.401), while a high positive direct effect was shown between PT and E (0.406). The leaves of ST presented a high positive direct effect on $I_{\text {sat }}(0.583)$ and WUE (0.578). In addition, a similar high negative direct effect was also observed between ST and VPD (-0.588). LET presented high positive direct effects on WUE (0.514), $V_{\text {cmax }}(0.483)$, and TPU (0.391). However, a relatively high negative direct effect was observed between LET and $R_{\mathrm{D}}$ (-0.362), VPD (-0.359), and $C_{\mathrm{i}}(-0.321)$. There was a direct effect with a relatively high negative magnitude of LCT on $V_{\mathrm{cmax}}(-0.478), I_{\mathrm{c}}(-0.416), J_{\max }(-0.371)$, and VPD $(-0.342)$, while the LCT has a higher positive direct effect on the $\Gamma^{*}(0.335)$ than photosynthetic capacity variables. The magnitude of negative direct effect guard cell width $(w)$ on $I_{\text {sat }}(-0.461)$ was observed. Also, a large relatively negative direct effect of guard cell length $(l)$ on $I_{\text {sat }}(-0.422)$ and $g_{\mathrm{i}}(-0.364)$ was found. However, $l$ also observed high positive direct effects on $C_{\mathrm{i}}(0.369)$. The stomatal density $(d)$ exhibited large negative direct effects on $g_{\mathrm{i}}(-0.379)$ and high positive direct effects on $J_{\max }$ (0.350) was found. The direct effect of TSP on the photosynthetic capacity variable was low, and the value range was from -0.179 to 0.185 .

Table 1. The correlation between leaf anatomical traits and photosynthetic parameter

\begin{tabular}{llllllllllll}
\hline $\begin{array}{l}\text { Parame } \\
\text { ters }\end{array}$ & LT & UCT & UET & PT & ST & LET & LCT & $w$ & $l$ & $d$ & TSP \\
\hline IQY & -0.044 & -0.336 & 0.296 & -0.343 & -0.010 & 0.000 & -0.232 & 0.175 & -0.315 & 0.232 & 0.103 \\
& ns & $*$ & ns & $*$ & ns & ns & ns & ns & $*$ & ns & ns \\
AQY & -0.024 & -0.322 & $0.386^{*}$ & -0.394 & 0.012 & 0.039 & -0.224 & 0.197 & -0.358 & 0.206 & 0.068 \\
\hline
\end{tabular}




\begin{tabular}{|c|c|c|c|c|c|c|c|c|c|c|c|}
\hline & $\mathrm{ns}$ & $*$ & & $*$ & ns & ns & ns & ns & * & ns & ns \\
\hline \multirow[t]{2}{*}{$\alpha$} & -0.033 & -0.332 & $0.351^{*}$ & -0.375 & 0.005 & 0.022 & -0.230 & 0.189 & -0.342 & 0.217 & 0.082 \\
\hline & ns & $*$ & & $*$ & $\mathrm{~ns}$ & ns & ns & ns & $*$ & $\mathrm{~ns}$ & $\mathrm{~ns}$ \\
\hline \multirow[t]{2}{*}{$P_{\max }$} & 0.178 & -0.108 & $0.324^{*}$ & -0.036 & 0.103 & 0.100 & -0.065 & -0.037 & -0.233 & 0.143 & -0.003 \\
\hline & $\mathrm{ns}$ & ns & & $\mathrm{ns}$ & ns & ns & $\mathrm{ns}$ & $\mathrm{ns}$ & ns & ns & $\mathrm{ns}$ \\
\hline \multirow[t]{2}{*}{$I_{\text {sat }}$} & -0.057 & -0.359 & 0.157 & -0.278 & 0.189 & -0.202 & -0.377 & -0.227 & -0.460 & 0.031 & -0.313 \\
\hline & $\mathrm{ns}$ & $*$ & $\mathrm{~ns}$ & ns & $\mathrm{ns}$ & ns & $*$ & ns & $* *$ & $\mathrm{~ns}$ & $*$ \\
\hline \multirow[t]{2}{*}{$I_{\mathrm{c}}$} & -0.064 & -0.143 & -0.324 & 0.164 & -0.008 & -0.336 & -0.174 & -0.323 & -0.071 & 0.017 & -0.150 \\
\hline & ns & $\mathrm{ns}$ & * & $\mathrm{ns}$ & ns & $*$ & ns & $*$ & & ns & ns \\
\hline \multirow[t]{2}{*}{$R_{\mathrm{D}}$} & 0.025 & -0.234 & -0.195 & 0.204 & 0.057 & -0.190 & -0.150 & -0.243 & -0.005 & 0.156 & 0.036 \\
\hline & $\mathrm{ns}$ & $\mathrm{ns}$ & $\mathrm{ns}$ & ns & $\mathrm{ns}$ & ns & $\mathrm{ns}$ & $\mathrm{ns}$ & $\mathrm{ns}$ & $\mathrm{ns}$ & ns \\
\hline \multirow[t]{2}{*}{$R_{\mathrm{d}}$} & 0.097 & 0.161 & -0.477 & 0.101 & 0.003 & -0.129 & 0.071 & -0.354 & 0.133 & -0.043 & -0.114 \\
\hline & ns & ns & $* *$ & $\mathrm{~ns}$ & $\mathrm{~ns}$ & ns & ns & $*$ & $\mathrm{~ns}$ & $\mathrm{~ns}$ & ns \\
\hline \multirow[t]{2}{*}{$V_{\text {cmax }}$} & -0.021 & -0.097 & 0.009 & 0.106 & 0.188 & 0.019 & -0.161 & 0.172 & -0.003 & 0.139 & 0.200 \\
\hline & $\mathrm{ns}$ & $\mathrm{ns}$ & $\mathrm{ns}$ & $\mathrm{ns}$ & ns & ns & $\mathrm{ns}$ & $\mathrm{ns}$ & $\mathrm{ns}$ & $\mathrm{ns}$ & $\mathrm{ns}$ \\
\hline \multirow[t]{2}{*}{$J_{\max }$} & -0.086 & -0.169 & -0.104 & -0.047 & -0.035 & -0.188 & -0.183 & -0.003 & -0.212 & $0.403^{*}$ & 0.246 \\
\hline & $\mathrm{ns}$ & ns & $\mathrm{ns}$ & ns & ns & ns & ns & ns & $\mathrm{ns}$ & $*$ & $\mathrm{~ns}$ \\
\hline \multirow[t]{2}{*}{ TPU } & -0.033 & -0.145 & -0.209 & 0.012 & 0.045 & -0.008 & 0.015 & -0.162 & 0.045 & 0.245 & 0.183 \\
\hline & $\mathrm{ns}$ & ns & ns & ns & ns & ns & ns & ns & ns & $\mathrm{ns}$ & ns \\
\hline \multirow[t]{2}{*}{$\Gamma^{*}$} & -0.210 & 0.181 & -0.086 & -0.159 & -0.239 & 0.228 & 0.119 & -0.163 & 0.104 & -0.285 & -0.276 \\
\hline & $\mathrm{ns}$ & $\mathrm{ns}$ & $\mathrm{ns}$ & $\mathrm{ns}$ & $\mathrm{ns}$ & ns & $\mathrm{ns}$ & $\mathrm{ns}$ & $\mathrm{ns}$ & $\mathrm{ns}$ & ns \\
\hline \multirow[t]{2}{*}{$g_{\mathrm{i}}$} & 0.207 & -0.433 & 0.311 & -0.092 & 0.371 & -0.071 & -0.420 & -0.006 & -0.301 & -0.149 & -0.301 \\
\hline & ns & $*$ & $\mathrm{~ns}$ & ns & ns & ns & $*$ & $\mathrm{~ns}$ & ns & $\mathrm{ns}$ & $\mathrm{ns}$ \\
\hline \multirow[t]{2}{*}{$C_{\mathrm{i}}$} & -0.066 & 0.108 & -0.396 & 0.257 & -0.125 & -0.164 & 0.187 & -0.053 & $0.311^{*}$ & -0.080 & 0.077 \\
\hline & $\mathrm{ns}$ & ns & $* *$ & $\mathrm{~ns}$ & $\mathrm{~ns}$ & $\mathrm{~ns}$ & $\mathrm{~ns}$ & $\mathrm{~ns}$ & & $\mathrm{~ns}$ & ns \\
\hline \multirow[t]{2}{*}{$g_{\mathrm{s}}$} & 0.140 & -0.111 & 0.278 & 0.073 & 0.044 & 0.146 & 0.053 & 0.005 & -0.085 & 0.174 & 0.116 \\
\hline & ns & ns & $\mathrm{ns}$ & $\mathrm{ns}$ & $\mathrm{ns}$ & $\mathrm{ns}$ & $\mathrm{ns}$ & $\mathrm{ns}$ & ns & $\mathrm{ns}$ & $\mathrm{ns}$ \\
\hline \multirow[t]{2}{*}{ VPD } & -0.023 & 0.071 & -0.372 & 0.281 & -0.143 & -0.230 & 0.106 & -0.063 & 0.221 & 0.052 & 0.148 \\
\hline & $\mathrm{ns}$ & $\mathrm{ns}$ & * & $\mathrm{ns}$ & $\mathrm{ns}$ & $\mathrm{ns}$ & ns & ns & $\mathrm{ns}$ & ns & $\mathrm{ns}$ \\
\hline \multirow[t]{2}{*}{ A } & 0.157 & -0.079 & $0.346^{*}$ & 0.007 & 0.049 & 0.203 & 0.047 & 0.048 & -0.117 & 0.149 & 0.094 \\
\hline & $\mathrm{ns}$ & ns & & ns & $\mathrm{ns}$ & ns & ns & ns & ns & ns & ns \\
\hline \multirow[t]{2}{*}{$\mathrm{E}$} & 0.196 & -0.057 & 0.224 & 0.191 & 0.031 & 0.068 & 0.106 & 0.002 & 0.003 & 0.164 & 0.158 \\
\hline & $\mathrm{ns}$ & ns & $\mathrm{ns}$ & $\mathrm{ns}$ & $\mathrm{ns}$ & ns & ns & ns & ns & ns & ns \\
\hline \multirow[t]{2}{*}{ WUE } & 0.049 & -0.115 & $0.350^{*}$ & -0.230 & 0.184 & 0.226 & -0.142 & 0.041 & -0.216 & 0.074 & -0.038 \\
\hline & $\mathrm{ns}$ & ns & & $\mathrm{ns}$ & $\mathrm{ns}$ & $\mathrm{ns}$ & ns & ns & ns & $\mathrm{ns}$ & $\mathrm{ns}$ \\
\hline
\end{tabular}

LT-leaf thickness, UCT-upper cuticle thickness, UET-upper epidermal thickness, PT-palisade tissue thickness,

ST-spongy tissue thickness, LET-lower epidermal thickness, LCT-lower cuticle thickness, $w$-guard cell width, $l$-guard cell length, $d$-stomatal density, TSP-total stomach pore area. $\mathrm{Ns}=$ non-significant. *, ** significant significance difference at $5 \%$ and $1 \%$ probability levels, respectively.

The estimates of each indirect effect of leaf anatomical trait on photosynthetic capacity via other leaf anatomical traits were presented in Fig 3(b). According to this figure, the values of the indirect effect of LT and ST on photosynthetic capacity

275 variables through other anatomical traits were lower than 0.300 . UCT revealed a 

negative indirect effect on IQY (-0.335), $I_{\text {sat }}(-0.343), \alpha(-0.326), g_{\mathrm{i}}(-0.319)$, and AQY $(-0.313)$ through other anatomical traits. UET indirectly exerted relatively high positive effects on AQY (0.357), A (0.345), $P_{\max }(0.325)$, and $\alpha(0.322)$ via other anatomical traits. Conversely, UET exhibited relatively high negative indirect effects on $R_{\mathrm{d}}(-0.479)$ and VPD (-0.367) via other anatomical traits. The indirect effects of PT on $g_{\text {i }}$ via other anatomical traits were negative and high (-0.329). There were indirect effects with a high negative magnitude of LCT on $I_{\text {sat }}$ and $g_{\mathrm{i}}$ via other anatomical traits(-0.359 and -0.340 , respectively). The $R_{\mathrm{d}}$ and $I_{\mathrm{c}}$ were influenced indirectly with a relatively high negative magnitude by $w$ via other anatomical traits $(-0.352$ and -0.307 , respectively). There was a relatively high positive indirect effect of $l$ on $C_{\mathrm{i}}(0.314)$ and negative on $I_{\text {sat }}(-0.450)$, AQY (-0.320) and $\alpha(-0.302)$ through other anatomical traits. In addition, a highly positive indirect effect of $d$ on $J_{\max }(0.399)$ was observed. The TSP presented a relatively high negative indirect effect on $I_{\text {sat }}(-0.312)$ and $g_{\mathrm{i}}(-0.344)$ through other anatomical traits.

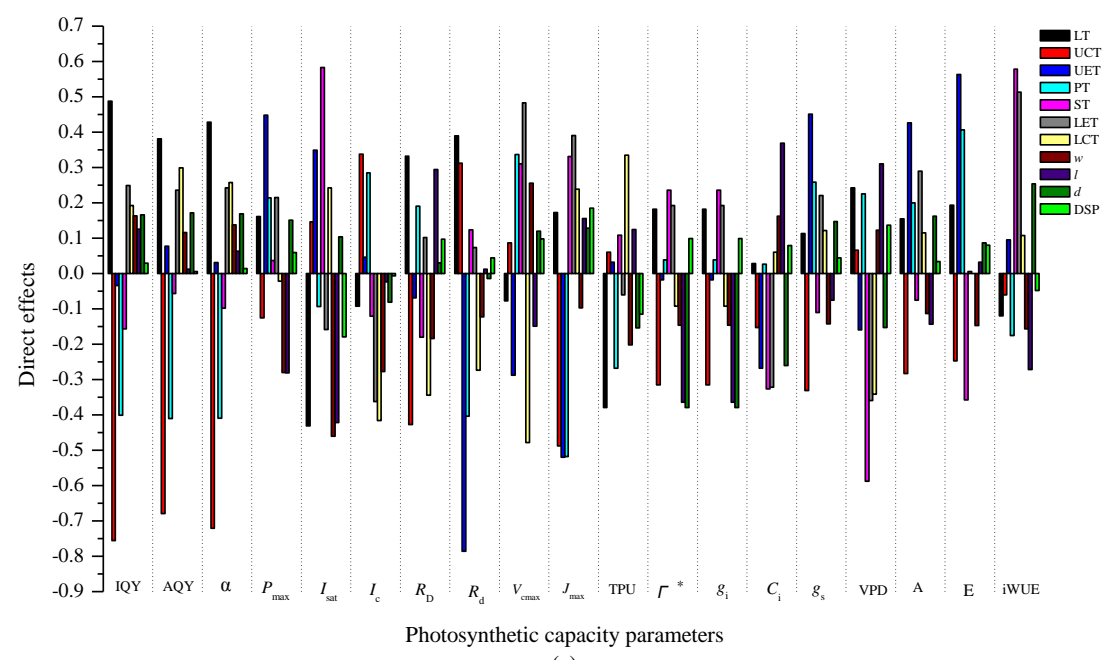

(a)

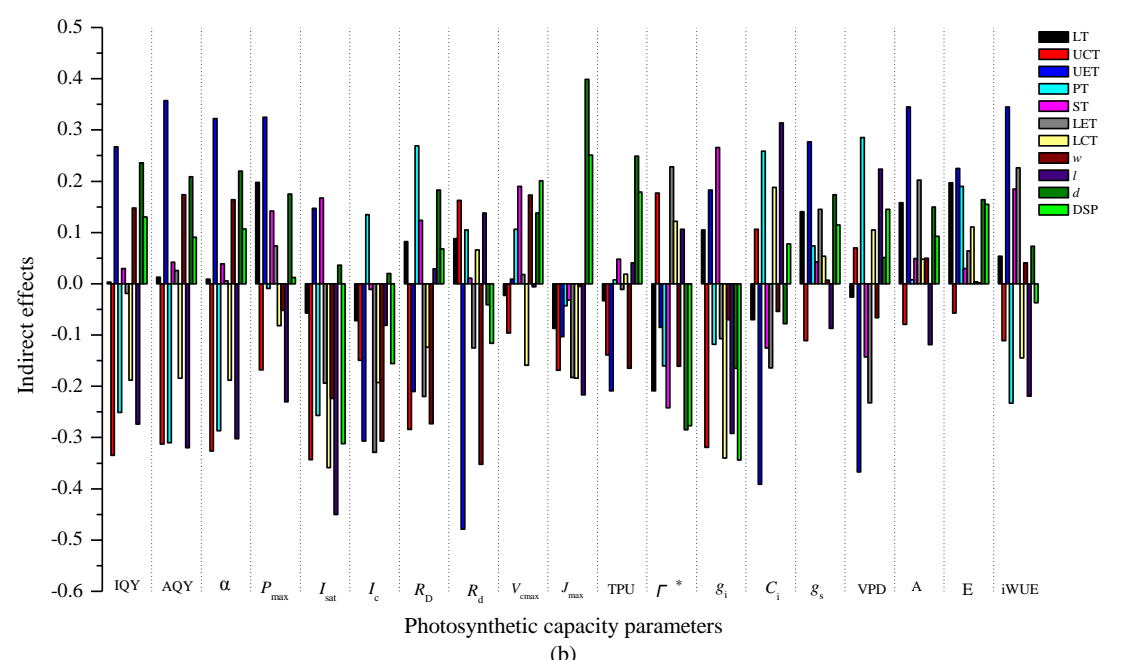

(b) 
Fig 3. Direct (a) and indirect (b) effects of each leaf anatomical traits through other traits on photosynthetic

$$
\text { capacity. }
$$

To identify the combined effect of leaf anatomical traits on photosynthetic parameters, a comprehensive evaluation was analyzed. Based on the evaluation values $\left(\mathrm{Q}_{\mathrm{i}}\right)$, the ranking of the comprehensive scores of relationships between photosynthetic capacity and leaf anatomical traits was shown in Table 2. The highest comprehensive score of direct effect was obtained by the LT followed by LET, $d$, TSP, ST, $L$, LCT, UET, PT, $W$, and UCT. For the comprehensive score of indirect effect on of leaf anatomical traits photosynthetic capacity, the $d$ held the highest comprehensive score, and ST was the second followed by LT, UET, TSP, PT, LET, $W$, LCT, $L$, and UCT. Similarly, for Pearson's correlation of comprehensive evaluation analysis, the results showed that the first comprehensive score was $d$, and the second was also ST. Then, the ranking order after the third was UET, LT, TSP, LET $W$, PT, LCT, $L$, and UCT.

\begin{tabular}{ccccccc}
\hline \multirow{2}{*}{$\begin{array}{c}\text { Anatomical } \\
\text { traits }\end{array}$} & \multicolumn{2}{c}{ Direct effects } & \multicolumn{2}{c}{ Indirect effects } & \multicolumn{2}{c}{ Pearson's correlation } \\
\cline { 2 - 6 } LT & Comprehensive score & Ranking & Comprehensive score & Ranking & Comprehensive score & Ranking \\
\hline UCT & 0.123 & 1 & 0.009 & 3 & 0.007 & 4 \\
UET & -0.168 & 11 & -0.125 & 10 & -0.137 & 11 \\
PT & -0.034 & 8 & 0.002 & 4 & 0.027 & 3 \\
ST & -0.056 & 9 & -0.021 & 5 & -0.049 & 8 \\
LET & 0.022 & 5 & 0.032 & 2 & 0.033 & 2 \\
LCT & 0.098 & 2 & -0.049 & 6 & -0.042 & 6 \\
$W$ & -0.020 & 7 & -0.079 & -0.102 & 9 \\
L & -0.062 & 10 & -0.060 & 7 & -0.045 & 7 \\
$d$ & -0.008 & 6 & -0.085 & 9 & -0.104 & 10 \\
TSP & 0.048 & 3 & 0.081 & 1 & 0.076 & -0.007 \\
\hline
\end{tabular}

310 LT-leaf thickness, UCT-upper cuticle thickness, UET-upper epidermal thickness, LET-lower epidermal thickness,

311 PT-palisade tissue thickness, ST-spongy tissue thickness, LCT-lower cuticle thickness, $w$-guard cell width,

$312 l$-guard cell length, $d$-stomatal density, TSP-total stomach pore area.

\section{Discussion}

314 Several studies involving gas exchange measurements of coffee leaves have been performed. These studies have pointed out that the photosynthetic capacity of coffee leaves varied with a variation environment (Ayalew, 2018; DaMatta, 2004; DaMatta and Ramalho, 2006; Kumar and Tieszen, 1980). For single coffee leaves, the saturating irradiance is between 300 and $700 \mathrm{mmol}$ photons $\mathrm{m}^{-2} \mathrm{~s}^{-1}$, with shade leaves showing a lower value than lower sun leaves (DaMatta, 2004; MATTA). This study found that the saturating irradiance of sun leaves was about $620 \mathrm{mmol}$ photons $\mathrm{m}^{-2} \mathrm{~s}^{-1}$, which was consistent with the result of the above mention. Quantum yields revealed the relationship between a given light-dependent product and the number of absorbed photons (Taiz and Zeige, 2006). Quantum yield is 0 when none of the light energy is used in photosynthesis. Quantum yield is 1 when all the absorbed light is used. Based 
on the results of YE (2007), the quantum yield decreased with $I$ increasing (Ye, 2007). Thus, the IQY was higher than AQY. In the past, there were several pertinent points about maximal photosynthetic rates of coffee leaves. For example, Kumar and Tieszen (1980) and Cannell (1985) have pointed out that the maximal photosynthetic rates of sun leaves of coffee are around $7 \mathrm{mmol} \mathrm{CO}_{2} \mathrm{~m}^{-2} \mathrm{~s}^{-1}$ and $8.8 \mathrm{mmol} \mathrm{CO}_{2} \mathrm{~m}^{-2} \mathrm{~s}^{-1}$, respectively (Cannell, 1985; Kumar and Tieszen, 1980). However, Bote et al. (2018) reported that the maximal photosynthetic rates of sun leaves of coffee were lower than $7 \mathrm{mmol} \mathrm{CO} \mathrm{m}^{-2} \mathrm{~s}^{-1}$ with a larger $\mathrm{N}$ supply (Bote et al., 2018). In this study, the maximal photosynthetic rates were lower than observations of Kumar and Tieszen (1980) and Cannell (1985) and consistent with the result of Bote et al. (2018). For coffee leaves, light saturation would lead to an excess of electron transport capacity (Martins et al., 2014). Therefore, higher $J_{\max }$ was observed under light saturation. In addition, the values of $V_{\mathrm{cmax}}$ and $J_{\max }$ were larger than Martins et al. (2014) reported result.

The correlation analysis is a great utility method for understanding the relationships between variables. In this study, significant correlations between photosynthetic capacity and leaf anatomical traits were observed, indicating that leaf anatomical traits could affect photosynthetic capacity. Despite the correlation coefficients could provide a good way to understand the relationships between variables, the cause and effect relationships between variables couldn't be estimated (Gonzalez-Paleo and Ravetta, 2018). Path analysis, which investigates the cause and effect relationship, can provide a detailed knowledge of positive and negative correlations between traits (Gonzalez-Paleo and Ravetta, 2018). The result of the path analysis was shown in Fig 3 , indicating that there were high-level direct and indirect effects of leaf anatomical traits on photosynthetic capacity. This may explain the importance of leaf structure in photosynthesis. In order to quantitatively evaluate the effect of each structure of leaf on photosynthesis, the comprehensive evaluation values are calculated by using the formula (8) introduced in the methods. The ordering comprehensive score showed that leaf thickness (LT) and stomatal density $(d)$ were the most important leaf anatomical traits for coffee leaf photosynthesis. For Arabica coffee, the photosynthetic is greatly limited by $\mathrm{CO}_{2}$ diffusion (DaMatta et al., 2007; Franck and Vaast, 2009b). The $\mathrm{CO}_{2}$ diffusion from the air to the leaf mesophyll is mainly modulated by the stomatal conductance $\left(\mathrm{g}_{\mathrm{s}}\right)$, which is associated with stomatal density $(d)$ (Lambers and Oliveira, 2019; Rodrigues et al., 2018). In fact, higher stomatal density will increase $\mathrm{g}_{\mathrm{s}}$ by increasing the same total pore area (Rodrigues et al., 2018). This may partly explain why the stomatal density $(d)$ had higher comprehensive evaluation values in the effect of coffee leaf photosynthesis.

The leaf thickness strongly positively correlated with the fraction of intercellular air space in the leaves (Niinemets, 1999). Given that the $\mathrm{CO}_{2}$ diffusion in the gaseous phase is about three orders of magnitude larger than in the liquid (Oguchi et al., 2018)(108). Thus, the diffusive resistance should not necessarily increase considerably with increasing leaf thickness (Smith et al., 1997). Moreover, due to the chloroplasts adhering to the inner surface of exposed mesophyll cell walls, thicker leaves provide space for more chloroplasts per unit leaf area (Lambers and Oliveira, 
2019) and possess more chloroplast surface area, which results in a substantial increase in carbon dioxide absorption because of a larger surface area for diffusion (Smith et al., 1997). Furthermore, thicker leaves may have higher total contents of Rubisco and leaf N per unit area (Niinemets and Sack, 2006). In this study, thick leaves have the highest most important direct effects on photosynthetic capacity as compared with other anatomical traits by using the CRITIC method. In addition to the result of path analysis, the relatively high direct effects of thick leaves (TL) on IQY, $\alpha$, $R_{\mathrm{d}}$, and AQY were also observed.

The structure of the leaf cuticle consists of epicuticular wax, birefringent wax embedded in cutin, cutin matrix, and pectic substance (Lee and Graham, 1986). The epicuticular wax can decrease light by scattering (Bote et al., 2018). The most cutin matrix in the cuticle is heterogeneous, and the areas of embedded waxes exhibit birefringence in polarized light (Lee and Graham, 1986). This heterogeneous structure of the leaf cuticle may affect epidermal focusing, allowing actinic light to penetrate deeper into the mesophyll (Bote et al., 2018). These findings most likely explained the significant relationship between cuticle thickness and photosynthetic gas exchange parameters. In addition, the cuticle thickness would increase resistance to $\mathrm{CO}_{2}$ diffusion (Miranda et al., 1981), and the negative relationships between UCT and LCT and photosynthetic parameters were also observed in this study.

The epidermal cell usually has a large transparent central vacuole and lacks mature chloroplasts, thus the light can directly pass from these cells into the mesophyll (Bote et al., 2018). However, these epidermal cells have various shapes, such as plano-convex, spherical, conical, or some other convex shape (Jackson et al., 2012). The curved outermost epidermal cell wall can affect the focal point within the leaf (Bote et al., 2018). However, the result of Brodersen and Vogelmann (2007) showed that there was no relative between the convexity of epidermal cells and the absorptance of diffuse light (Brodersen and Vogelmann, 2007). Although two contradictory hypotheses have been proposed with regard to the impacts of epidermal cells on photosynthesis, this study examined epidermal lens effects on many photosynthetic parameters and elucidated cells property plays an important role in photosynthetic capacity by using the CRITIC method.

When intrinsic quantum yields are high, light capture and utilization are most efficient(Herrmann et al., 2020). However, structural changes of a leaf may affect light absorption (Herrmann et al., 2020). For example, thicker mesophyll would enhance light absorptance in leaves, due to greater internal light scattering (Lambers and Oliveira, 2019). Because photon irradiance absorptance varied with variation chlorophyll concentration of leaf (Lambers and Oliveira, 2019), the quantum yield would be affected by chlorophyll concentration. Most chlorophylls were contained in the palisade cells. This could explain the significant relationship between quantum yield and PT. In addition, measurements of light gradients in leaves showed that palisade tissue (PT) facilitates the penetration of direct sunlight (Vogelman et al., 1996). The result of this study also indicated that a large relatively negative direct effect of PT on IQY, AQY, and $J_{\max }$ were observed.

The concentration of $\mathrm{CO}_{2}$ in the mesophyll is affected by air temperature, and each 
degree rise in temperature above $24^{\circ} \mathrm{C}$ results in a $20 \mathrm{ppm}$ rise in $\mathrm{CO}_{2}$ concentration (Nunes et al., 1968). However, Khairi and Hall's (1976) studies of citrus photosynthesis showed that mesophyll conductance to $\mathrm{CO}_{2}$ decreased with temperature increase when the temperature increased from $22^{\circ} \mathrm{C}$ to around $40^{\circ} \mathrm{C}$ (Khairi and Hall, 1976). In the analysis of effects of leaf anatomical traits on photosynthetic capacity, the spongy tissue thickness (ST) had larger indirect effects and Pearson's correlation comprehensive score, suggesting that spongy tissue thickness (ST) plays an important role in the photosynthetic process. In addition, Martins et al. (2014) showed that mesophyll thickness and stomatal attributes related to water flux and gas exchange per leaf area (Martins et al., 2014), which is consistent with the result of this study. On the other hand, the irregular shaped spongy cells alternating with air spaces increases light absorption due to the optical path length through a leaf increase (Oguchi et al., 2018)(105), and these absorbed light will be advanced for photosynthesis (Brodersen and Vogelmann, 2007; Cannell, 1985). Although there was little relationship between spongy tissue thickness (ST) and photosynthetic parameters, the high direct spongy tissue thickness (ST) effects upon $I_{\text {sat }}$, WUE, and VPD was observed.

Leaf structure plays a key role in determining the conductance of $\mathrm{CO}_{2}$ through the leaf because changes in leaf structure will change gas diffusion within the leaves (Evans et al., 1994). Moreover, the $\mathrm{CO}_{2}$ diffusion conductance is also influenced by the density and arrangement of the stomata (Oguchi et al., 2018). For the coffee leaf, the net carbon assimilation rate (A) greatly is governed by diffusive conductances of $\mathrm{CO}_{2}$, thus the photosynthesis of the coffee leaf was largely limited by a diffusive factor(Araujo et al., 2008). Traditionally, stomata have been considered as one of the major roles in controlling $\mathrm{CO}_{2}$ diffusive (Araujo et al., 2008) and were a key parameter in the photosynthesis of $C$. $\operatorname{arabica}($ Ayalew, 2018). Among the various stomatal characters, stomatal density plays a major role in gas exchange and photosynthesis (Pompelli et al., 2010). In this study, it is shown that stomatal density had the highest comprehensive scores compared with other anatomical traits in indirect effects and Pearson's correlation comprehensive evaluation. In addition, structural modification of the stomata is one of the key factors affecting stomatal conductance (Taiz and Zeige, 2006). The result of this study also showed that the guard cell length $(l)$ significantly correlated positively with $C_{\mathrm{i}}$.

For light absorption, although the result of Martins et al. (2014) showed that the guard cell length did not change in response to light treatments (Martins et al., 2014), there was a significant correlation with IQY and AQY. The coordination between increased initiation of stomata cells and expansion of epidermal cells was observed in coffee leaves, implying that there was an optimization of the trade-off between transpirational costs and $\mathrm{CO}_{2}$ assimilation (Martins et al., 2014). In addition, stomatal size and density largely controlled the leaf's diffusive conductance to $\mathrm{CO}_{2}$, and the balance between the $\mathrm{CO}_{2}$ required for photosynthesis and the level of water availability was also determined by stomatal traits (Rodrigues et al., 2018). Thus, lower epidermal stomatal density had a significant correlation with photosynthetic parameters or direct effects and indirect effects on photosynthetic parameters. 
Moreover, these traits also had larger comprehensive scores in a comprehensive evaluation. This means that stomatal density was a key parameter in the regulation photosynthesis of $C$. arabica.

\section{Conclusion}

Many leaf anatomical traits significantly affected photosynthetic parameters. This result provided holistic relationships between leaf anatomical traits and photosynthetic parameters in coffee. It is tempting to suggest that these relationships might to some extent explain the photosynthetic behaviour of coffee (Coffea arabica L.). The relationships between leaf anatomical traits and photosynthetic parameters emphasize the importance of leaf anatomy in determining photosynthesis at the tissue level. Moreover, these correlations between leaf anatomical traits and photosynthetic parameters were useful to explore the impact of different anatomical features on photosynthetic efficiency and accordingly provide some information to design leaf anatomy for enhanced photosynthetic efficiency. To a certain extent, path analysis and comprehensive evaluation could indicate interrelationship between photosynthetic capacity and leaf anatomical traits. However, the causal interrelationship between photosynthetic parameters and leaf anatomical traits is less clear. In spite of this, the result of the study also suggests that improvements of the photosynthetic performance of coffee through selecting thinker leaf and higher stomatal density that might support higher photosynthetic capacity could be a useful strategy to facilitate the selection of promising genotypes with enhanced coffee growth and production.

\section{Author contributions}

Z.X. and G.M. conceptualization and research design; X.H. and J.L. project administration;M.Z.and L.S. investigation and fieldwork, Z.X. analysed the data and wrote the manuscript; H.M. and H.Z. resources; all theauthors read and edited the manuscript, and approved the final version.

\section{Funding}

This research was funded by the Basic Research Project of Dehong Tropical Agriculture Research Institute of Yunnan (DTARI-JJ2020-02) and DR155 Coffee Variety Industrialization Technology Integration and Application Demonstration (202003AD150006), and National Tropical Plants Germplasm Resource Center.

\section{References}

Akhkha A, Reid I, Clarke DD, Dominy P. 2001. Photosynthetic light response curves determined with the leaf oxygen electrode: minimisation of errors and significance of the convexity term. Planta 214, 135-141.

Araujo WL, Dias PC, Moraes GABK, Celin EF, Cunha RL, Barros RS, Damatta FM. 2008. Limitations to photosynthesis in coffee leaves from different canopy positions. Plant Physiol Biochem 46, 884-890.

Ayalew B. 2018. Impact of shade on morpho-physiological characteristics of coffee plants, their pests and diseases: A review. African Journal of Agricultural Research 13, 2016-2024.

Batos, Vilotic, Orlovic, Miljkovic. 2010. Inter and intra-population variation of leaf stomatal traits of quercus robur 1. In northern serbia. ARCH BIOL SCI 2010,62(4), 1125-1136.

Beer JW, Muschler RG, Somarriba E, Kass D. 2001. Shade management in coffee and cacao plantations- a review. Journal of Experimental Botany 52, 2057-2065. 
Bolhar-Nordenkampf H, Draxler G. 1993. Functional leaf anatomy. Photosynthesis and production in a changing environment: Springer, 91-112.

Boom, Tholen, Zhu XG. Opinion: prospects for improving photosynthesis by altering leaf anatomy. Bote AD, Zana Z, Ocho FL, Vos J. 2018. Analysis of coffee (Coffea arabica L.) performance in relation to radiation level and rate of nitrogen supply II. Uptake and distribution of nitrogen, leaf photosynthesis and first bean yields. European journal of Agronomy 92, 107-114.

Brodersen CR, Vogelmann TC. 2007. Do epidermal lens cells facilitate the absorptance of diffuse light? American Journal of Botany 94, 1061-1066.

Cannell M. 1985. Physiology of the coffee crop. Coffee, 108-134.

DaMatta FM. 2004. Ecophysiological constraints on the production of shaded and unshaded coffee: a review. Field Crops Research 86, 99-114.

DaMatta FM, Ramalho JDC. 2006. Impacts of drought and temperature stress on coffee physiology and production: a review. Brazilian Journal of Plant Physiology 18, 55-81.

DaMatta FM, Ronchi CP, Maestri M, Barros RS. 2007. Ecophysiology of coffee growth and production. Braz. J. Plant Physiol 19, 485-510.

Diakoulaki D, Mavrotas G, Papayannakis L. 1995. Determining objective weights in multiple criteria problems: The critic method. Computers \& Operations Research 22, 763-770.

Evans JR, Caemmerer S, Setchell BA, Hudson GS. 1994. The relationship between CO2 transfer conductance and leaf anatomy in transgenic tobacco with a reduced content of Rubisco. Functional Plant Biology 21, 475-495.

Farquhar GD, Caemmerer SV, Berry JA. 1980. A biochemical model of photosynthetic CO2 assimilation in leaves of $\mathrm{C} 3$ species. Planta 149, 78-90.

Franck N, Vaast P. 2009a. Limitation of coffee leaf photosynthesis by stomatal conductance and light availability under different shade levels. Trees structure and function.

Franck Ns, Vaast P. 2009b. Limitation of coffee leaf photosynthesis by stomatal conductance and light availability under different shade levels. Trees 23, 761-769.

Gonzalez-Paleo L, Ravetta DA. 2018. Relationship between biochemical and photosynthetic traits with Asian soybean rust. Photosynthetica 90, 3925-3940.

GU L, Pallardy GS, TU K, Law BE, Wullschleger SD. 2010. Reliable estimation of biochemical parameters from C-3 leaf photosynthesis-intercellular carbon dioxide response curves. Plant, Cell \& Environment 33, 1852-1874.

Gu L, Sun Y. 2014. Artefactual responses of mesophyll conductance to CO2 and irradiance estimated with the variable $\mathrm{J}$ and online isotope discrimination methods. Plant Cell \& Environment 37, 1231-1249.

Guohua W, Hu Z, Yuesong W. 2017. Implementation of Partial Least Squares Regression in SPSS Software. Statistics \& Decision, 67-71.

Herrmann HA, Schwartz JM, Johnson GN. 2020. From empirical to theoretical models of light response curves - linking photosynthetic and metabolic acclimation. Photosynthesis Research 145, 5-14.

ICO. 2015. Coffee in China. In: Organization IC, ed. International Coffee Council. Milan, Italy: International Coffee Organization.

Jackson D, Skillman J, Vandermeer J. 2012. Indirect biological control of the coffee leaf rust, Hemileia vastatrix, by the entomogenous fungus Lecanicillium lecanii in a complex coffee agroecosystem. Biological Control 61, 89-97. 
James S, Bell D. 2001. Leaf morphological and anatomical characteristics of heteroblastic Eucalyptus globulus ssp. globulus (Myrtaceae). Australian Journal of Botany 49, 259-269.

Khairi MMA, Hall AE. 1976. Comparative Studies of Net Photosynthesis and Transpiration of Some Citrus Species and Relatives. Physiologia plantarum 36, 35-39.

Kumar D, Tieszen LL. 1980. Photosynthesis in Coffea arabica. I. Effects of light and temperature. Experimental Agriculture 16, 13-19.

Lambers H, Oliveira RS. 2019. Plant physiological ecology. Switzerland: Springer.

Lee DW, Graham R. 1986. Leaf optical properties of rainforest sun and extreme shade plants. American Journal of Botany 73, 1100-1108.

Ma GR, Liu HQ, Tian SM, Bai XH, Zhao MZ, Li JH, Xiao ZW. 2019. Soil nutrient status in coffee plantation of Yunnan and the main factors related with quality of green coffee beans. Journal of Plant Nutrition and Fertilizers 25, 154-161.

Martins SC, Galmés J, Cavatte PC, Pereira LF, Ventrella MC, DaMatta FM. 2014. Understanding the low photosynthetic rates of sun and shade coffee leaves: bridging the gap on the relative roles of hydraulic, diffusive and biochemical constraints to photosynthesis. PloS one 9, e95571.

MATTA FD. Ecophysiological constraints on the production of shaded and unshaded coffee: a review. Field Crops Research.

Miranda V, Baker NR, Long SP. 1981. Anatomical variation along the length of the Zea mays leaf in relation to photosynthesis. New Phytologist 1981, 595-605.

Niinemets Ü. 1999. Research review. Components of leaf dry mass per area - thickness and density alter leaf photosynthetic capacity in reverse directions in woody plants. New Phytologist 144, 35-47.

Niinemets Ü, Sack L. 2006. Structural determinants of leaf light-harvesting capacity and photosynthetic potentials. Progress in Botany 67.

Nunes M, Bierhuizen J, Ploegman C. 1968. Studies on productivity of coffee: I. Effect of light, temperature and $\mathrm{CO} 2$ concentration on photosynthesis of Coffea arabica. Acta botanica neerlandica 17, 93-102.

Oguchi R, Onoda Y, Terashima I, Tholen D. 2018. Leaf anatomy and function. In: III WWA, Terashima I, eds. The leaf: a platform for performing photosynthesis. Switzerland: Springer, 97-139.

Patricia BL, Laclau JP, Beri C, Mietton L, Muniz MRA, Arenque BC, De Cassia Piccolo M, Lionel JM, Bouillet JP, Nouvellon Y. 2014. Photosynthetic and anatomical responses of E ucalyptus grandis leaves to potassium and sodium supply in a field experiment. Plant, Cell \& Environment 37, 70-81.

Pompelli M, Martins S, Celin E, Ventrella M, DaMatta F. 2010. What is the influence of ordinary epidermal cells and stomata on the leaf plasticity of coffee plants grown under full-sun and shady conditions? Brazilian Journal of Biology 70, 1083-1088.

Rodrigues WP, Silva JR, Ferreira LS, Machado Filho JA, Figueiredo FA, Ferraz TM, Bernado WP, Bezerra LB, de Abreu DP, Cespom L, Ramalho JC, Campostrini E. 2018. Stomatal and photochemical limitations of photosynthesis in coffee (Coffea spp.) plants subjected to elevated temperatures. Crop and Pasture Science 69, 317-325.

Smith WK, Vogelmann TC, DeLucia EH, Bell DT, Shepherd KA. 1997. Leaf form and photosynthesis. BioScience 47, 785-793.

Sun Y, Gu L, Dickinson RE, Pallardy SG, Baker J, Cao Y, DaMatta FM, Dong X, Ellsworth D, Goethem DV, Jensen AM, Law BE, Loos R, Martins SCV, Norby RJ, Warren J, Weston D, Winter K. 2014. Asymmetrical effects of mesophyll conductance on fundamental photosynthetic 
parameters and their relationships estimated from leaf gas exchange measurements. Plant, Cell \&

590 Environment 37, 978-994.

591 Taiz L, Zeige E. 2006. Plant Physiology. Sunderland Massachusetts Sinauer Associates, Inc.

592 Vogelman TC, Nishio JN, Smith WK. 1996. Leaves and light capture: light propagation and gradients 593 of carbon fixation within leaves. Trends in plant science 1, 65-70.

594 Wang Q, Chun A, J., Fleisher D, Reddy V, Timlin D, Resop J. 2017. Parameter Estimation of the 595 Farquhar-von Caemmerer-Berry Biochemical Model from Photosynthetic Carbon Dioxide 596 Response Curves. Sustainability 9, 1228.

597 Ye Z-P. 2007. A new model for relationship between irradiance and the rate of photosynthesis in Oryza 598 sativa. Photosynthetica 45, 637-640.

599 Ye Z-P. 2010. A review on modeling of responses of photosynthesis to light and $\mathrm{CO}_{2}$. Chinese Journal 600 of Plant Ecology 34, 727-740.

601 Ye Z-P, Yu Q. 2008. Comparison of new and several classical models of photosynthesis in response to 602 irradiance. Journal of Plant Ecology (Chinese Version), 149-154.

603 Zhang H, Schroder JL, Fuhrman JK, Basta NT, Storm DE, Payton ME. 2005. Path and Multiple 604 Regression Analyses of Phosphorus Sorption Capacity. Soil science society of America journal 69, 605 96-106.

606 